\title{
Depletion of Cystine in Cystinotic Fibroblasts by Drugs Enclosed in Liposomes
}

\author{
JEAN DeBROHUN BUTLER, ${ }^{(3)}$ ) FRANK TIETZE, FRANCOISE PELLEFIGUE, STEPHEN P. \\ SPIELBERG, AND JOSEPH D. SCHULMAN \\ Section on Human Biochemical and Developmental Genetics, National Institute of Child Health and Human \\ Development and the Section on Intermediary Metabolism, National Institute of Arthritis, Metabolism and \\ Digestive Diseases, National Institutes of Health, Bethesda, Maryland, USA
}

\begin{abstract}
Summary
Lysosomally compartmentalized cystine can be removed from cystinotic cells by the use of reducing agents. In further investigation of means for converting cystine to a form or forms capable of penetrating the lysosomal membrane, a number of chemical agents either enclosed in phospholipid vesicles (liposomes) or free in solution were presented to cystinotic cells in tissue culture. After a $\mathbf{2}$-hr incubation, cystine content of cultured cystinotic cells was generally reduced more effectively by such agents in liposomes than in the medium. The most effective combination was cysteamine (MEA) in liposomes: a $0.5 \mathrm{mM}$ dose of $\mathrm{MEA}$ reduced the cystine content of cystinotic cells $86 \%$ more when enclosed in liposomes than when dissolved at the equivalent dose in the medium. This observation could not be repeated when serum was omitted from the incubation medium, indicating that serum binds or otherwise inactivates cysteamine and that the liposome-enclosed cysteamine is protected from this action. Other liposome-entrapped compounds tested showed little if any depletion of intracellular cystine beyond that caused by non-liposome-enclosed drug action. Some agents increased the intracellular cystine content. Others of low molecular weight proved to be poorly retained by liposomes, a factor which may have been responsible for their relative ineffectiveness. Cysteamine, which is positively charged at neutral pH, was retained effectively when enclosed in "negative" liposomes made by inclusion of phosphatidic acid in the lipid mixture.

[ ${ }^{35}$ S]Cysteamine $(2.5 \mu \mathrm{Ci}, 23 \mu \mathrm{g} / \mathrm{g})$, both free and enclosed in liposomes, was injected intravenously into mice. Ratios of MEA uptake by phagocytic as compared to non-phagocytic tissues $(e . g .$, kidney/brain) were higher in liposome-injected than in control mice, indicating preferential uptake of liposomeenclosed MEA by selected tissues of mice corresponding to those exhibiting high levels of cystine accumulation in cystinotic patients. Cell fractionation of liver and kidney from MEAliposome-treated mice showed a much higher proportion of radioactivity in the mitochondrial-lysosomal fraction than in control animals receiving the same drug dissolved in medium.
\end{abstract}

\section{Speculation}

Drugs such as MEA and dithiothreitol (DTT) have been used in treatment of cystinotic patients, as they are effective in reducing intracellular accumulations of cystine in vitro. They are, however, toxic, particularly to brain tissue. Cyctine is known to accumulate in large amounts in certain actively endocytic tissues in cystinosis. The administration of liposomes containing drugs aimed at reducing or otherwise altering the accumulated cystine might prove advantageous as a therapeutic measure if selectivity of uptake into target tissues could be improved, particularly since these lipid carriers are nonallergenic and degradable by lysosomal enzymes after their uptake by phagocytic cells.

Cystinosis is a recessive, autosomally inherited disease, the fundamental cause of which remains unknown. There is an accumulation of cystine in lysosomes, with particularly heavy concentrations in actively endocytic or phagocytic tissues such as kidney, liver, spleen, and white blood cells (25-27). These elevated cystine concentrations are apparently toxic to certain cellular functions. During the first few years of life, the principal effects of abnormal cystine storage are growth retardation, photophobia, hypothyroidism, and, most importantly, the renal Fanconi syndrome with subsequent renal failure (classic nephrophathic cystinosis) (24). Adolescent onset and benign adult cystinosis also shows intracellular accumulation of cystine but generally of lesser magnitude, with clinical symptoms correspondingly less severe or absent altogether. The existence of these variant forms of cystinosis suggests that a partial reduction of intracellular cystine content in the nephropathic cystinotic patient might therefore prove to be of clinical value.

Cystine can be removed from cystinotic fibroblasts by agents such as MEA, cystamine, DTT, and vitamin C $(4,7,11,15$, 32). The first three compounds have known toxicity in vivo (13). We have explored the action of these and other compounds on cystinotic cells in tissue culture and the distribution of $\left[{ }^{35} \mathrm{~S}\right]$ cysteamine in normal mice, comparing the free drug to its liposome-enclosed form.

Liposomes are artificial phospholipid vesicles first described by Bangham et al. in 1965 (2). Water-soluble compounds can be incorporated in the interior of the structure if they are present in the solution in which the vesicles are formed by entrapment in the aqueous spaces confined by the lipid lamellae. The use of liposomes to transport material into cells is being explored currently in several laboratories $(8,18,21,33)$. Theoretically, such a carrier would be nonallergenic and biodegradable, and would afford the possibility of selective uptake of any entrapped agent by endocytic target cells. To our knowledge no studies related to the potential use of liposome-enclosed agents in the treatment of cystinosis have been reported.

\section{MATERIALS AND METHODS}

All chemicals were of the highest purity available. Dipalmitoyl phosphatidylcholine and phosphatidic acid were obtained from Analabs, New Haven, CN; cholesterol and 6,8-thioctic acid, reduced form (lipoic acid), from Sigma Chemical Co., St. Louis, MO; mercaptoethanolamine (MEA), DTT, cysteine, $N$-acetylcysteine, cystamine (oxidized MEA), 5,5'-bis-dithionitrobenzoic acid, pyridoxal phosphate (vitamin $\mathbf{B}_{6}$ ), 2,3-dimercaptopropanol (British antilewisite), penicillamine, and reduced glutathione (GSH) from Calbiochem, San Diego, CA; vitamin $\mathrm{C}$ and 
sodium sulfite from Fisher Scientific Co., Silver Spring, MD; Lamino acid oxidase (L-AOD), and catalase from Boehringer Mannheim, Germany; NCS tissue solubilizer from Amersham/ Searle, Arlington Heights, IL. $\left[{ }^{35}\right.$ S Cysteamine (sp act 165 $\mathrm{mCi} / \mathrm{g}$ ) was custom synthesized by Amersham and its purity confirmed by high voltage electrophoresis. $\left[{ }^{35}\right.$ S Cystine $(5 \mathrm{mCi} /$ $0.35 \mathrm{mg}$ ) and "Aquasol" scintillation fluid were purchased from New England Nuclear, Boston, MA.

\section{LIPOSOME PREPARATION}

Liposomes were made by modification of published methods $(2,21,30,33)$. Negatively charged, saturated phosphatidyl choline-cholesterol-phosphatidic acid liposomes were prepared in a molar ratio of 7:2:1 (dipalmitoyl phosphatidylcholine-cholesterol-phosphatidic acid). A mixture of $30 \mathrm{mg}$ dipalmitoyl phosphatidylcholine, $4.4 \mathrm{mg}$ cholesterol, and $4.0 \mathrm{mg}$ phosphatidic acid, dissolved in chloroform, was placed in a thick walled glass test tube and dried in a thin film under nitrogen by rotary evaporation at $37^{\circ}$. Five milliliters of a cold isotonic aqueous solution (usually flushed with nitrogen) of the compound to be enclosed in liposomes was placed in the test tube and sonicated for $12 \mathrm{~min}$ in 3-min bursts in a Branson Sonifier (Heat Systems model W140), using the microtip probe and a setting of 2 , keeping the solution cold and under a stream of nitrogen. Drugs that were soluble only in organic solvents were introduced in chloroform and dried in a film with the phosphatidylcholine, cholesterol, and phosphatidic acid, and sonicated in isotonic phosphate-buffered saline (PBS) pH 7.4. The liposomes were then filtered through a $1.2 \mu \mathrm{m}$ Millipore filter. The filtered liposomes (approximately $0.5-2 \mu \mathrm{m}$ in diameter) were then centrifuged in a Beckman L5-65 ultracentrifuge at $65,000 \mathrm{rpm}$, $4^{\circ}$, for $30 \mathrm{~min}$ to separate them from the drug in solution. The pellet was rinsed with PBS, and washed by resuspending in $5 \mathrm{ml}$ PBS and recentrifuging. The final pellet was resuspended in 5 $\mathrm{ml}$ PBS and assayed for drug content as described below. The effect of cloudy liposome suspensions on absorbance could be eliminated by use of $2 \%$ deoxycholate solution in the assay buffer and/or by using matching amounts of liposomes made in saline in the reference cuvette. Liposomes were used immediately on the day of preparation and leftover portions were stored at $4^{\circ}$ under nitrogen. Leakage of compounds from liposomes was detected after 1 or more days by recentrifuging the remaining liposomes, resuspending the pellet to the same volume, and reassaying for the drug under investigation.

\section{DRUG ASSAYS}

All drugs containing free thiol groups (MEA, DTT, GSH, British anti-Lewisite, $N$-acetylcysteine, and reduced lipoic acid) were assayed by the method of Ellman (6). Cystamine, the disulfide form of MEA, was analyzed according to the Zahler and Cleland method (34). Vitamin C was determined by absorbance at $260 \mathrm{~nm}$, pyridoxal phosphate at $390 \mathrm{~nm}$, and L-AOD and catalase at $280 \mathrm{~nm}$.

\section{TISSUE CULTURE}

Cystinotic cells were grown to confluency at $37^{\circ}$ in $95 \%$ air/ $5 \% \mathrm{CO}_{2}$ atmosphere in $25 \mathrm{~cm}^{2}$ plastic Falcon flasks with minimum essential medium (Eagle's no. 2) containing added nonessential amino acids, $2 \mathrm{mM}$ glutamine, $10 \%$ fetal calf serum, and either neomycin or penicillin-streptomycin-chlorotetracycline. At confluency, medium was removed and replaced with $4 \mathrm{ml}$ identical medium containing [ ${ }^{35}$ S]cystine $(5 \mu \mathrm{Ci} / \mathrm{ml})$. After $24 \mathrm{hr}$ of incubation, control flasks received an additional $1 \mathrm{ml}$ PBS, whereas experimental flasks received drug-containing liposomes in $1 \mathrm{ml}$ PBS or an equal dose of drug in $1 \mathrm{ml}$ PBS. Experiments were done at two drug levels, a higher one of $0.3-$ $1 \mathrm{mM}$, and a lower one of $0.1-0.2 \mathrm{mM}$, and with two incubation periods, $2 \mathrm{hr}$ and $20 \mathrm{hr}$. For harvesting, medium was removed, the monolayer washed three times with PBS and the cells trypsinized with $0.25 \%$ trypsin in PBS. The loosened cells were collected in test tubes and washed three times with $3 \mathrm{ml}$ PBS by centrifuging and decanting. The final pellet was sonicated in 0.5 $\mathrm{ml}$ freshly prepared solution of $N$-ethylmaleimide (NEM) $(25$

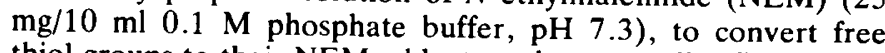
thiol groups to their NEM adducts and prevent disulfide formation. Proteins were precipitated with addition of $0.5 \mathrm{ml} 3 \%$ sulfosalicylic acid. After centrifugation at $1000 \times \mathrm{g}$ for $10 \mathrm{~min}$ the supernatant was removed and stored frozen. The pellet was dissolved in $0.5 \mathrm{ml} 1 \mathrm{~N} \mathrm{NaOH}$, brought to $0.5 \mathrm{~N} \mathrm{NaOH}$ with $\mathrm{H}_{2} \mathrm{O}$, and total protein determined by the method of Lowry et al. (16). The supernatants were analyzed for radioactive cystine, glutatione disulfide, NEM-cysteine, and NEM-glutathione by high voltage paper electrophoresis using Whatman no. 3 paper and a Gilson Electrophorator at $4 \mathrm{kV}$ for $2 \mathrm{hr}$ in $7.8 \%$ formic acid, $\mathrm{pH}$ 1.8. After drying, relevant areas were cut from the paper strip, placed in Econofluor (New England Nuclear scintillation fluid) and radioactivity determined in a liquid scintillation counter (Beckman LS-250). Results were calculated as counts per min per mg cell protein and further expressed as percentage of control flasks, whether plain controls or non-liposome drug controls. All data points represent the mean of at least two flasks; controls and some experimentals represent four flasks. In some experiments, employing unlabeled cystine, the cystine content of cells after sonication and reaction with NEM and precipitation with SSA was determined by the cystine binding protein assay of Oshima et al. (17).

\section{IN VIVO STUIDIES}

$\mathrm{AKR} / \mathrm{M}$ mice were injected by tail vein while under brief ether anesthesia with either $\left[{ }^{35} \mathrm{~S}\right] \mathrm{MEA}$-liposomes or PBS containing the same amount of $\left.{ }^{35} \mathrm{~S}\right] \mathrm{MEA}$. At $3 \mathrm{hr}$ the mice were killed by cervical dislocation and the relevant tissues dissected and weighed. A portion of each tissue was dissolved in $1 \mathrm{ml}$ of the tissue solubilizer NCS, and $15 \mathrm{ml}$ Aquasol were added. Radioactivity was determined after correction for quenching and results calculated as disintegrations per mg wet weight tissue. Data were then expressed as ratios of radioactivity found in selected actively phagocytic organs (liver, lung, spleen, or kidney) to that found in poorly phagocytic or nonphagocytic organs (muscle or brain). In an additional experiment, two control and two experimental animals were injected with ${ }^{35}$ S]MEA as outlined above. At $2 \mathrm{hr}$, samples of liver and kidney were dissected and immediately homogenized in $0.25 \mathrm{M}$ sucrose at $4^{\circ}$ with a Dounce homogenizer. Four cell fractions were obtained by ultracentrifugation $(3,12,27)$ : a nuclear fraction at $600 \times g$ for $10 \mathrm{~min}$, a mitochondrial-lysosomal fraction at $27,000 \times g$ for $10 \mathrm{~min}$, a microsomal fraction at $100,000 \times g$ for $1 \mathrm{hr}$, and the cell cytoplasmic fraction. Total radioactivity was determined in each fraction and expressed both as disintegrations per mg wet weight tissue, and as the ratio of counts in the mitochondrial-lysosomal fraction to that in the cytoplasmic fraction.

\section{RESULTS}

The characteristics of lipid vesicles (liposomes) can be varied depending on the choice of lipids used in their composition. Preliminary investigation involving mixtures of saturated or unsaturated phospholipids with additional positively charged (stearylamine) or negatively charged (phosphatidic acid) compounds was carried out to determine a suitable and preferable combination of lipids. The four types of liposomes explored are listed in Table 1. Each type was made up in PBS and tested for toxicity by incubation with cells in tissue culture. The third type of liposome was chosen for subsequent experiments; these negative dipalmitoyl phosphatidylcholine-cholesterol liposomes were of small size, $(0.5-2 \mu \mathrm{m})$, rigid in character, and free of the self-aggregation often observed in positive liposomes. Type 
III liposomes were also the least toxic when added to fibroblasts in culture.

As a test of the system, liposomes incorporating $\left[{ }^{14} \mathrm{C}\right]$ dextran were incubated with cystinotic cells in tissue culture. $\left[{ }^{14} \mathrm{C}\right]$ Dextran enclosed in liposomes is taken up at a rate 2-4 times greater than $\left[{ }^{14} \mathrm{C}\right]$ dextran dissolved in the incubation medium (Fig. 1). This gives assurance that the contents of negatively charged dipalmitoyl phosphatidylcholine-cholesterol liposomes could be preferentially accumulated by cystinotic fibroblasts in culture.

The results of treatment of cultured cystinotic cells with drugs aimed at lowering of lysosomally trapped cystine are presented in Figure 2. When such drugs were enclosed in liposomes the cystine content of the cells as compared to a saline control was generally lower than that observed when the same dose of drug was solubilized in the incubation medium. This effect is more noticeable after $2 \mathrm{hr}$ of incubation than after $20 \mathrm{hr}$. An exception to this general observation is seen with DTT where cystine content of cells appeared increased by treatment with drugliposomes in comparison to drug dissolved in medium. DTT and L-AOD + catalase in solution and in liposomes at $2 \mathrm{hr}$ and lipoic acid at $20 \mathrm{hr}$ under the conditions selected caused 2- to 3fold increases in cellular cystine compared to control cells. Reasons for these increases are not apparent; the result with DTT was particularly surprising since others have shown (7) and we have confirmed that this drug will deplete the cystine content of cystinotic cells under different conditions. Vitamin C and DTT are known to decrease the storage of cystine in cystinotic cells when used in repeated doses over longer periods of time $(7,15)$.

The greatest overall effect on the cystine content of cystinotic cells was produced by treatment with MEA and cystamine (MEA disulfide), resulting in a lowering of cystine content by approximately 50-90\% relative to control cells (Fig. 2). After 2-hr incubations, MEA and cystamine brought about the greatest reduction of cellular cystine when presented enclosed in liposomes; at the higher doses employed these two drugs lowered cellular cystine $86 \%$ and $47 \%$ more, respectively, than when dissolved in solution. When MEA was incubated with cells in medium lacking serum, the drug was still active in lowering cellular cystine but the greater depletion of cystine by liposome-enclosed MEA compared to that in solution was largely eliminated. These results suggest that MEA binding to serum by disulfide exchange is reduced by enclosing the drug in lipid vesicles. Liposome-enclosed vitamin $\mathrm{C}$ at a dose of 0.16 $\mathrm{mM}$ caused intracellular cystine to be $73 \%$ lower after $2 \mathrm{hr}$ than the level produced by the same amount of vitamin $C$ in solution, whereas liposome-penicillamine lowered cell cystine $47 \%$ more than soluble penicillamine at a dose of $0.2 \mathrm{mM}$; these differences were less impressive at higher doses. Other compounds tested exhibited only slight or no changes in intracellular cystine when incubated with liposome-enclosed drugs in comparison with non-liposome-enclosed drugs. As an additional control, saline liposomes incubated with cystinotic cells are seen to lower cellular cystine content not more than $10 \%$ relative to saline controls.

Table 1. Types of liposomes

\begin{tabular}{|c|c|c|c|}
\hline Type & Phospholipid & Cholesterol & $\begin{array}{c}\text { Charged } \\
\text { lipid }\end{array}$ \\
\hline I (-) unsaturated & Egg lecithin & + & $\begin{array}{l}\text { Phosphatidic } \\
\text { acid }\end{array}$ \\
\hline II (+) unsaturated & Egg lecithin & + & Stearylamine \\
\hline III $^{2}(-)$ saturated & $\begin{array}{l}\text { Dipalmitoyl } \\
\text { lecithin }\end{array}$ & + & $\begin{array}{l}\text { Phosphatidic } \\
\text { acid }\end{array}$ \\
\hline IV (+) saturated & $\begin{array}{l}\text { Dipalmitoyl } \\
\text { lecithin }\end{array}$ & + & Stearylamine \\
\hline
\end{tabular}

' Molar ratio of phospholipid cholesterol/charged lipid, 7:2:1.

${ }^{2}$ Chosen for subsequent experiments.

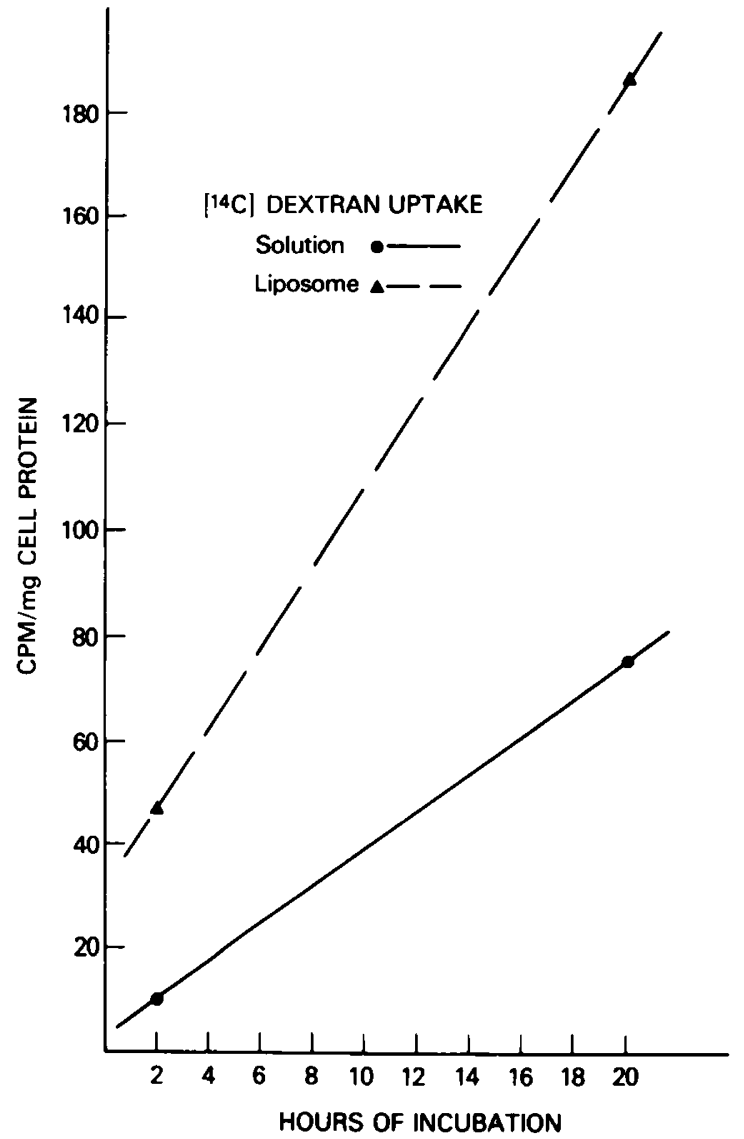

Fig. 1. Uptake of $\left[{ }^{14} \mathrm{C}\right]$ dextran by cystinotic cells in tissue culture. Cells were incubated at $37^{\circ}$ with equal amounts of $\left[{ }^{14} \mathrm{C}\right]$ dextran in the medium $(-\bullet)$ and enclosed in liposomes $(\mathbf{\Delta - - \Delta )}$.

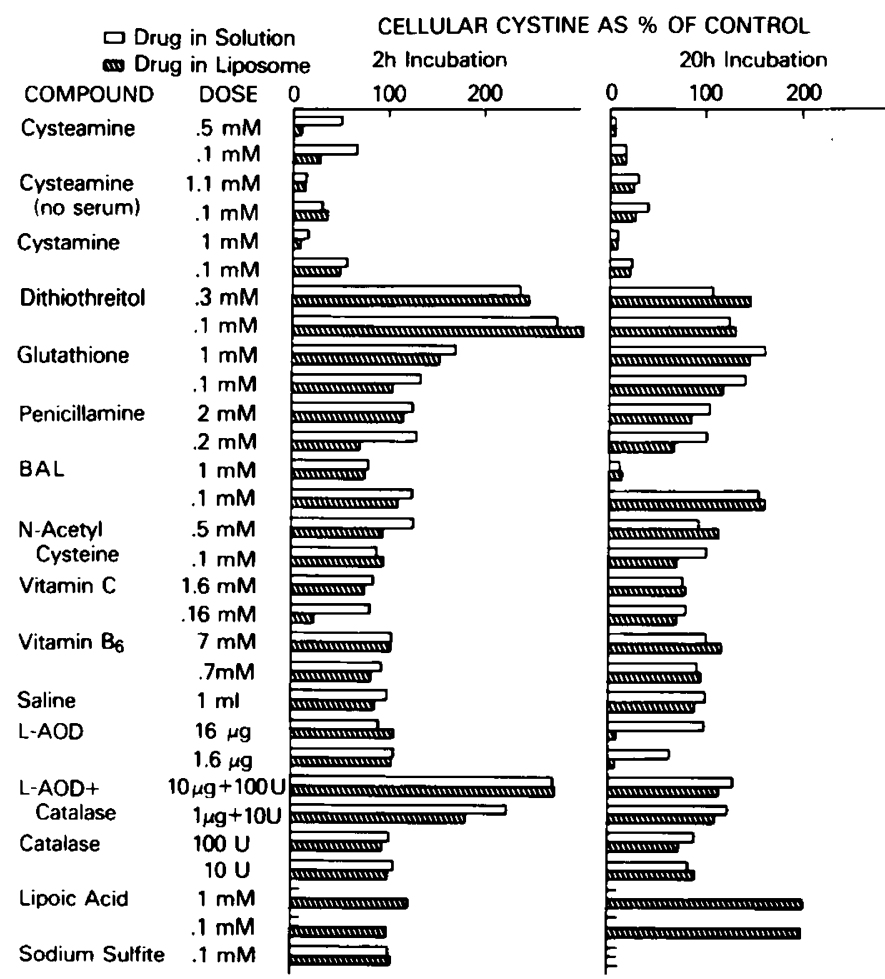

Fig. 2. Cystine content of cystinotic cells in tissue culture treated with drugs in solution (open bars) and enclosed in liposomes (shaded bars), expressed as percentage of cystine found in control cells. Controls were grown under the same conditions with the addition of saline in place of drug dissolved in saline with no liposomes. 
In 20-hr incubations, British anti-Lewisite and L-AOD caused a striking decrease of cellular cystine as seen in Figure 2. However, the cells exhibited extensive toxic effects which may have been responsible for the low cystine content. The effect of L-AOD is of interest in this regard. When catalase was included with L-AOD in liposomes the cells remained fully viable. Since the reaction of L-AOD with amino acids produces hydrogen peroxide, it appears probably that this toxic effect may be due to hydrogen peroxide production. In experiments not recorded here it was found that large amounts of liposomes and extended incubation periods $(>24 \mathrm{hr})$ resulted in similar cytotoxic effects, which could also be prevented by inclusion of catalase. These experiments suggest that cell damage may result from excessive hydrogen peroxide production during phagocytosis of large numbers of phospholipid vesicles.

As described in Materials and Methods, labeling of cystinotic cells with $\left[{ }^{35} \mathrm{~S}\right]$ cystine followed by reaction with NEM made possible an estimation of the relative intracellular levels of GSH, cysteine, and glutathione, disulfide form (GSSG), in addition to cystine itself. Data not shown here indicated that the first three named compounds showed little variation from control levels when treated as described in Figure 2. The few exceptions were as follows. Treatment with MEA resulted generally in lowered cysteine, GSH, and GSSG levels, ranging from $10 \%$ to $65 \%$ below control levels. Treatment with DTT resulted in levels of cysteine, GSH, and GSSG higher than controls $(10 \%$ to $250 \%)$. Vitamin $\mathrm{C}$ treatment seemed to specifically increase the cysteine levels 2 - to 4 -fold, whereas total glutathione levels were relatively unchanged. The mechanisms involved in these alterations were not explored further.

Most compounds used in these experiments are of low molecular weight and some might be expected to leak from lipid vesicles. All liposomes were used on the day of preparation, and the remainder was stored at $4^{\circ}$ under nitrogen. The remainder was later centrifuged and resuspended to the same volume and assayed for drug content. Results show that most of the compounds tested demonstrated some leakage under these conditions (Table 2). Those showing the greatest latency (most stable enclosure) were MEA, vitamin C, and GSH. MEA was the smallest molecule used except for sulfite, having a molecular weight of 113.6. It carries a positive charge at physiologic $\mathrm{pH}$. That MEA enclosure was $\mathrm{pH}$ dependent is shown in Figure 3; its retention in liposomes is substantially better at neutral $\mathrm{pH}$ than at acid or alkaline pH. The ionic state of both the solute molecule and of the liposome probably plays a role in drug retention by lipid vesicles.
To measure tissue distribution of free and liposome enclosed drug, $\left[{ }^{35}\right.$ S]MEA was incorporated into liposomes or dissolved directly in PBS, and injected into mice as described in Materials and Methods. Six experimental and seven control animals received $0.4 \mathrm{ml}$ of the liposome suspension or PBS containing 0.5 mM MEA $\left(2.5 \mu \mathrm{Ci}\left[{ }^{35} \mathrm{~S}\right] \mathrm{MEA}\right)$. The animals were killed at $3 \mathrm{hr}$ and tissues were analyzed as described in Materials and Methods. Results (Table 3) show that radioactivity was preferentially localized in phagocytic rather than nonphagocytic tissues. The ratio of radioactivity in kidney, liver, lung, and spleen compared to brain was significantly higher when the injected drug was enclosed in liposomes rather than when freely dissolved in PBS. When these same tissues are compared with muscle, there are significant ratio differences for lung and spleen, whereas for kidney and liver the trends are similar but do not reach significant levels. In an additional experiment, four mice were injected as above with equal doses of [ $\left.{ }^{35} \mathrm{~S}\right] \mathrm{MEA}$, either enclosed in liposomes or dissolved in PBS. After 2-hr the mice were killed; the livers and kidneys were immediately dissected and homogenized in cold $0.25 \mathrm{M}$ sucrose and fractionated by centrifugation as described in Materials and Methods. The radioactivity found in the mitochondrial-lyosomal fraction was 5-fold greater in liver and 2-fold greater in kidney when the radioactive MEA

Table 2. Leakage of small molecules from dipalmityol-L- $\alpha$ lecithin liposomes

\begin{tabular}{lcccc}
\hline \multicolumn{1}{c}{ Drug } & $\begin{array}{c}\text { Mol } \\
\text { wt }\end{array}$ & $\begin{array}{c}\text { Conc., } \\
\mathrm{mM}\end{array}$ & $\begin{array}{c}\text { Time under } \\
\mathrm{N}_{2} \text { at } 4^{\circ} \text {, days }\end{array}$ & $\begin{array}{c}\text { \% Drug } \\
\text { remaining } \\
\text { enclosed }\end{array}$ \\
\hline Glutathione & 307.3 & 6 & 8 & 70 \\
Dithiothreitol & 154.3 & 10 & 5 & 12 \\
& & 3 & 5 & 40 \\
Cysteamine & 113.6 & 10 & 2 & 106 \\
& & 3 & 2 & 70 \\
Sodium sulfite & 126.0 & 1 & 1 & 14 \\
& & 0.3 & 1 & 8 \\
Penicillamine & 149.2 & 1 & 1 & 20 \\
Lipoic acid & 149.2 & 16 & 1 & 4 \\
& 206.3 & 1 & 1 & 25 \\
British anti-lewisite & 124.2 & 10 & 1 & 44 \\
& & & & \\
Vitamin C & 176.1 & 8 & 6 & 80 \\
$N$-Acetylcysteine & 163.2 & 1 & 1 & 10 \\
Vitamin $B_{6}$ & 265.2 & 7 & 3 & 10 \\
\hline
\end{tabular}

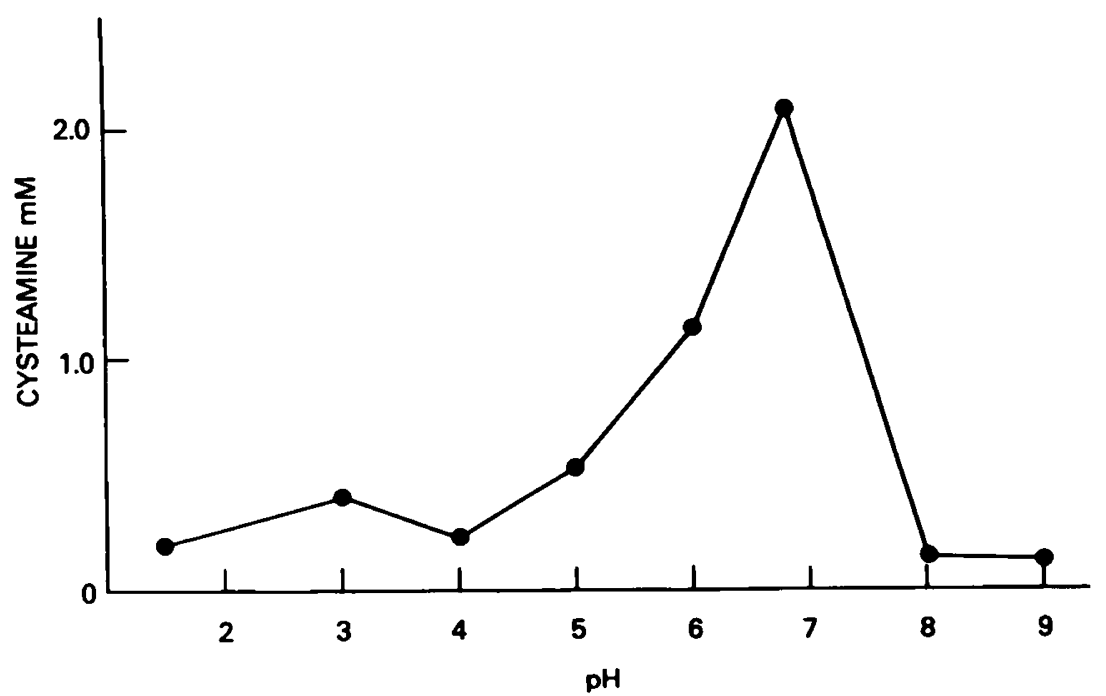

Fig. 3. pH dependence of cysteamine retention by liposomes. Liposomes were produced in Materials and Methods. The dried lipid films were sonicated in $13 \mathrm{mM}$ cysteamine and adjusted to the $\mathrm{pH}$ indicated with $\mathrm{HCl}$. Liposomes were centrifuged and washed once with PBS and assayed for thiol content with 5,5'-bis-dithionitrobenzoic acid. 
was injected enclosed in liposomes than when dissolved in PBS (Fig. 4). Conversely, radioactivity in the cell cytoplasm decreases in both liver and kidney when MEA is introduced via liposomes rather than free in solution.

\section{DISCUSSION}

Use of liposomes for treatment of diseases has been discussed in recent reports. For example, Rahman and Wright (22) have successfully used liposome-encapsulated chelating agents in mice to remove toxic metals. In cancer chemotherapy, drug-carrier potential of liposomes has been explored by Gregoriadis $e t$ al. (10) with the finding that more liposomes are taken up by malignant than by normal tissue. Enzymes have been entrapped in liposomes for potential treatment of certain lysosomal storage diseases (9). Cohen et al. (5) were able to introduce hexosaminidase A into white blood cells of Tay-Sachs patients when enclosed in liposomes whereas free enzyme was not endocytozed. Papahadjopoulos et al. (19) tested the effect of cyclic AMP liposomes on cells in tissue culture. When enclosed in liposomes, cyclic AMP retarded growth to a much greater degree than did cyclic AMP in solution.

A recent paper by Poste and Papahadjopoulos (20) explores the use of liposomes as drug carriers. According to their findings, the use of negatively charged "solid" (dipalmitoyl phosphatidylcholine) lipid vesicles gave almost exclusive endocytic uptake by 3 T3 mouse fibroblasts in tissue culture. In contrast, "fluid" (dioleyl phosphatidylcholine) neutral liposomes more frequently fused with the cell membrane, thereby entering the cytoplasm rather than being directed to the lysosome. Liposomes used in the present work were the "solid" type containing dipalmitoyl phosphatidylcholine and were negatively charged by inclusion of phosphatidic acid. They were chosen for the reasons cited above as well as for other favorable characteristics. For example, saturated fatty acids are not subject to autoxidation as are unsaturated fatty acids; hence the use of dipalmitoyl phosphatidylcholine liposomes avoids some of the toxic effects of peroxides or epoxides on cells in tissue culture. In addition, negatively charged liposomes made with phosphatidic acid were free of aggregation characteristics encountered in positive liposomes made with stearylamine. Furthermore, the addition of cholesterol contributes a well known condensing effect on phospholipid membranes, making the liposome even less permeable to solutes (31). The above considerations, together with the ionic attraction between enclosed solute and charged liposome (Fig. 3), may account for the substantial degree of latency exhibited by several of the drug-containing liposomes used in these experiments despite the low molecular weights of the enclosed solutes.

Experiments presented in this paper indicate that administration of certain chemical agents enclosed in liposomes is more

Table 3. Uptake of free or liposome-enclosed $\left[{ }^{35} S\right]$ cysteamine by mouse tissues

\begin{tabular}{lccl}
\hline & \multicolumn{2}{c}{ Ratio of cpm/mg wet wt tissue } \\
\cline { 2 - 4 } Tissue pairs & Controls & $\begin{array}{c}\text { Liposome } \\
(\mathrm{SE})^{2}\end{array}$ & \multicolumn{1}{c}{$P$ value $^{3}$} \\
& $(\mathrm{SE})^{1}$ & $6.3 \pm 1.1$ & $<0.005$ \\
& $4.8 \pm 0.3$ & $5.1 \pm 1.3$ & $\mathrm{NS}$ \\
Kidney/brain & $4.1 \pm 1.4$ & $24.6 \pm 5.4$ & $<0.005$ \\
Kidney/muscle & $17.7 \pm 1.5$ & $20.3 \pm 6.8$ & $\mathrm{NS}$ \\
Liver/brain & $15.2 \pm 5.3$ & $9.0 \pm 1.0$ & $<0.0005$ \\
Liver/muscle & $4.7 \pm 0.7$ & $7.3 \pm 1.4$ & $<0.0025$ \\
Lung/brain & $4.0 \pm 1.2$ & $19.3 \pm 7.6$ & $<0.0005$ \\
Lung/muscle & $5.0 \pm 0.4$ & $16.2 \pm 7.7$ & $<0.0025$ \\
Spleen/brain & $4.3 \pm 1.4$ & & \\
Spleen/muscle & & &
\end{tabular}

${ }^{1}$ Six animals.

2 Seven animals.

${ }^{3} \mathrm{NS}=P>0.05$.

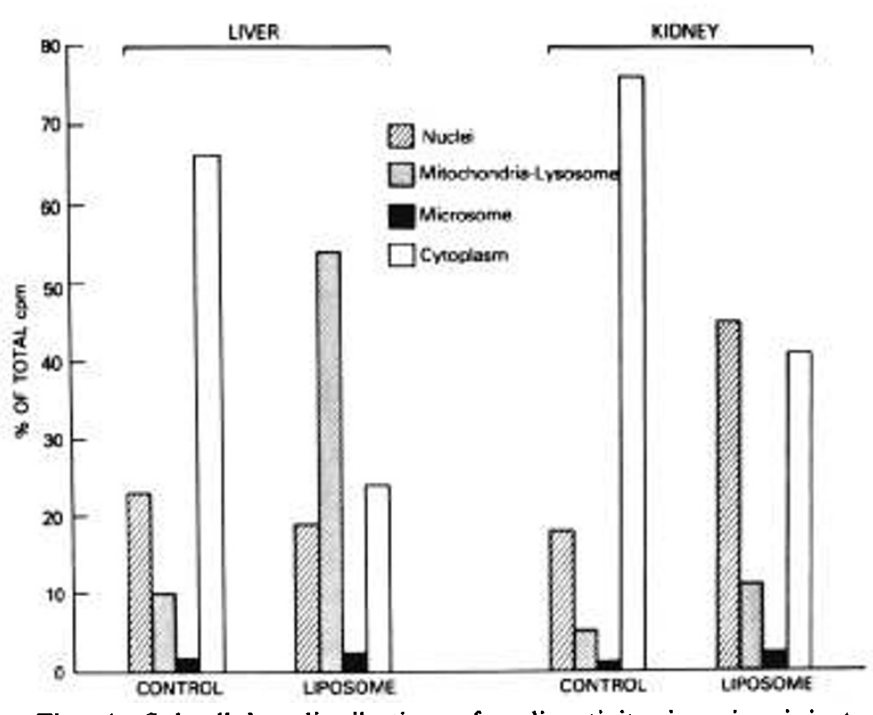

Fig. 4. Subcellular distribution of radioactivity in mice injected intravenously with equal doses of $\left.{ }^{35} S\right]$ MEA solubilized in PBS as control or enclosed in liposomes. At $2 \mathrm{hr}$ the mice were killed; livers and kidneys were dissected, homogenized in $0.25 \mathrm{M}$ sucrose, and fractionated by centrifugation as noted in Materials and Methods. Radioactivity found in each cell fraction is expressed as percentage of counts per min found in the whole tissue.

effective in lowering of cystine in cystinotic cells in tissue culture than treatment using an equivalent dose in solution. The lipid vesicles serve as a targeting agent for the introduction of therapeutic drugs to the lysosome since they are preferentially removed by phagocytizing tissues and are localized in the lysosomes where cystine is stored in cystinosis. Furthermore, they protect the enclosed agents from reaction or degradation in medium in vitro (and presumably in vivo). The in vivo studies indicate that cysteamine incorporated into liposomes will be largely taken up by phagocytic cells and concentrated in the lysosomes, whereas the same drug in solution will appear mainly in the cell cytoplasm. The results presented in this paper were promising in this respect but do not seem sufficiently dramatic to justify direct exploration in clinical trials on cystinotic patients at this time. Improvements in the selectivity of liposome uptake by tissues and in liposomal latency are needed before therapeutic treatment of cystinosis might be feasible by this approach. For example, Cohen et al. (5) added an immunoglobulin coating to enzyme-containing liposomes and found increased uptake by white blood cells. Cytotoxicity will result when large amounts of liposomes or L-AOD are incubated with cells in tissue culture. Phagocytosis and the enzymatic L-AOD reaction are accompanied by production of $\mathrm{H}_{2} \mathrm{O}_{2}$ (23). In both cases the toxicity was alleviated by incorporation of catalase in liposomes presented to the cells, suggesting that this toxicity may be due to effects of excessive hydrogen peroxide production. Such manipulation of the composition of the lipid vesicle used in therapy may also lead to more efficacious results.

The precise mechanism of action of drugs which reduce the amount of cystine accumulating in cystinotic cells is poorly understood. It is assumed that in the case of thiol liposomeenclosed agents such as MEA, lysosomal enzymes disrupt the liposome vesicle, releasing the drug intralysosomally; cystine is thereby reduced to free cysteine which escapes from the lysosome by diffusion either as such or as a mixed disulfide $(14,32)$. Vitamin $C$ does not reduce cystine directly and its mechanism of cystine depletion is obscure. Goldman et al. (7) and Aaron et al. (1) were able to deplete intracellular cystine in cystinotic fibroblasts by the use of the reducing agent, DTT. These results were subsequently confirmed in our laboratory under the conditions they described. In the present experiments under different conditions an opposite effect was demonstrated with cystine 
accumulating to levels 2 - to 3 -fold higher than in untreated cystinotic cells; no ready explanation for this observation is apparent.

Accumulation of cystine in cystinotic cells is a dynamic process $(28,29)$. The cause of its entrapment in cystinotic cells has eluded investigators in spite of extensive efforts. Since the level of cystine storage in cystinotic cells in tissue culture can be manipulated by the use of chemical agents encapsulated in lipid vesicles, this technique may prove an additional tool to further investigate the fundamental causes of cystinosis.

\section{CONCLUSION}

The effects on cystine content of certain sulfhydryl-containing and other chemical agents enclosed in lipid vesicles or dissolved in isotonic solution were studied in vitro on cystinotic cells. Some agents were more effective when presented in lipid vesicles than when they were free in solution. Liposome-enclosed cysteamine accumulated preferentially in certain mouse tissues and in lysosomes in vivo. The results do not appear to be dramatic enough to warrant clinical trials at this time on cystinotic patients using liposome-enclosed agents; further investigation into methods for increasing the magnitude and selectivity of liposomal uptake is required.

\section{REFERENCES AND NOTES}

1. Aaron, K., Goldman, H., and Scriver, C. R.: Cystinosis; new observations 1. Adolescent (type III) form. 2. Correction of phenotypes in vitro with dithiothreitol. In: N. A. J. Carson and D. N. Raine: Inherited Disorders of Sulphur Metabolism (Churchill Livingston, London, 1971).

2. Bangham, A. D., Standish, M. M., and Watkins, J. C.: Diffusion of univalent ions across the lamellae of swollen phospholipids. J. Mol. Biol., 13: 238 (1965).

3. Claude, A.: Fractionation of Mammalian liver cells by differential centrifugation. J. Exp. Med., 84: 51 (1946)

4. Clayton, B. E., and Patrick, A. D.: Use of dimercaprol or penicillamine in the treatment of cystinosis. Lancet, ii: 909 (1961).

5. Cohen, C. M., Weissman, G., Hoffstein, S., Awasthi, Y. C., and Scrivastava, S. K.: Introduction of purified hexosaminidase $A$ into Tay-Sachs leucocytes by means of immuglobulin-coated liposomes. Biochemistry, 15: 452 (1976).

6. Ellman, G. L.: Tissue sulfhydryl groups. Arch. Biochem. Biophys., 82: 70 (1959).

7. Goldman, H., Scriver, C. R., Aaron, K., and Pinsky, L.: Use of dithiotreitol to correct cystine storage in cultured cystinotic fibroblasts. Lancet, $i: 811$ (1970).

8. Gregoriadis, G.: Drug entrapment in liposomes. FEBS Lett., 36: 292 (1973).

9. Gregoriadis, G., Leathwood, P. D., and Ryman, B. E.: Enzyme entrapment in liposomes. FEBS Lett., 14: 95 (1971).

10. Gregoriadis, G., Wills, E. J., Swain, C. P., and Tavill, A. S.: Drug-carrier potential of liposomes in cancer chemotherapy. Lancet, ii: 1313 (1974).

11. Hambraeus, L., and Broberger, $O$.: Penicillamine treatment of cystinosis. Acta. Paediat. Scand., 56: 243 (1967).

12. Hogeboom, G. H., Schneider, W. C., and Palade, G. E.: Cytochemical studies of mammalian tissues. J. Biol. Chem., 172: 619 (1948).

Copyright (c) 1978 International Pediatric Research Foundation, Inc. 0031-3998/78/0012-0001\$02.00/0
13. Jackson, J. F.: Toxicity of sulfhydryl compounds to cultured human lymphocytes. Exp. Cell Res., 61: 468 (1970)

14. Jackson, R. C., Harrap, K. R., and Smith, C. A.: Binding of glutathione and cysteine to cellular protein by mixed disulfide bonds. Biochem. J., 110: 37P (1968).

15. Krolls, W. A. and Schneider, J. A.: Decrease in free cystine content of cultured cystinotic fibroblasts by ascorbic acid. Science, 186: 1040 (1974).

16. Lowry, O. H., Rosebrough, N. J., Farr, A. L., and Randall, R. J.: Protein measurement with the Folin phenol reagent. J. Biol. Chem., 193: 265 (1951).

17. Oshima, R. G., Willis, R. C., Furlong, C. E., and Schneider, J. A.: Binding assays for amino acids: The utilization of a cystine binding protein from Escherichia coli for the determination of acid-soluble cystine in small physiological samples. J. Biol. Chem., 249: 6033 (1974).

18. Papahadjapoulos, D., and Miller, N.: Phospholipid model membranes. Biochim. Biophys. Acta, 135: 624 (1967).

19. Papahadjopoulos, D., Poste, G., and Mayhew, E.: Cellular uptake of cyclic AMP captured within phospholipid vesicles and effect on cell-growth behavior. Biochim. Biophys. Acta, 363: 404 (1974).

20. Poste, G., and Papahadjopoulos, D.: Lipid vesicles as carriers for introducing materials into cultured cells: Influence of vesicle lipid composition on mechanism(s) of vesicle incorporation into cells. Proc. Natl. Acad. Sci. U. S. A., 73: 1603 (1976).

21. Rahman, Y. E., Rosenthal, M. W., Cerny, E. A., and Moretti, E. S. Preparation and prolonged tissue retention of liposome-encapsulated chelating agents. J. Clin. Lab. Med., 83: 640 (1974).

22. Rahman, Y. E., and Wright, B. J.: Liposomes containing chelating agents. J Cell Biol., 65: 112 (1975).

23. Root, R. K., Metcalf, J., Oshima, N., and Chance, B.: $\mathrm{H}_{2} \mathrm{O}_{2}$ release from human granulocytes during phagocytosis. J. Clin. Invest., 55: 945 (1975).

24. Schneider, J. A.: Clinical aspects of cystinosis. In: J. D. Schulman: Cystinosis, p. 11, DHEW Publication No. (NIH) 72-249 (U.S. Government Printing Office, Washington, DC, 1973).

25. Schneider, J. A., Bradley, K. H., and Seegmiller, J. F.: Increased cystine in leucocytes from individuals homozygous and heterozygous for cystinosis. Science, 157: 1321 (1967).

26. Schneider, J. A., Rosenbloom, F. M., Bradley, K. H., and Seegmiller, J. E. Increased free-cystine content of fibroblasts cultured from patients with cystinosis. Biochem. Biophys. Res. Commun., 29: 527 (1967).

27. Schneider, W. C.: Intracellular distribution of enzymes. J. Biol. Chem., 176: 259 (1948).

28. Schulman, J. D., and Bradley, K. H.: Cystinosis: Therapeutic implications of in vitro studies of cultured fibroblasts. J. Pediat., 78: 933 (1971).

29. Schulman, J. D., Bradley, K. D., and Seegmiller, J. E.: Cystine: Compartmentalization within lysosomes in cystinotic leucocytes. Science, 166: 1157 (1969).

30. Sessa, G., and Weissmann, G.: A model for structure-linked latency. J. Biol. Chem., 245: 3295 (1970).

31. Szabo, G.: Dual mechanism for the action of cholesterol on membrane permeability. Nature, 252: 47 (1974).

32. Thoene, J. G., Oshima, R. G., Crawhall, J. C., Olson, D. L.: Cystinosis: Intracellular cystine depletion by aminothiols in vitro and in vivo. J. Clin. Invest., 58: 180 (1976).

33. Weismann, V. N.: In: J. M. Tager, G. Houghwinkel, and W. T. Daems: Enzyme Therapy in Lysosomal Storage Diseases, p. 85 (North-Holland Publishing Co., Amsterdam, 1974).

34. Zahler, W. L., and Cleland, W. W.: A specific and sensitive assay for disulfides. J. Biol. Chem., 243: 716 (1968).

35. Requests for reprints should be addressed to: Jean DeBrohun Butler, M.D., Building 10, Room 13N-260, National Institutes of Health, Bethesda, MD 20014 (USA).

36. Received for publication February 11, 1977

37. Accepted for publication May 6, 1977. 